УДК 528.94(477.75)

\title{
ОЦЕНКА ВЕГЕТАЦИОННОГО ИНДЕКСА NDVI НА ТЕРРИТОРИИ ГОРОДА ФЕДЕРАЛЬНОГО ЗНАЧЕНИЯ СЕВАСТОПОЛЬ В 2017 ГОДУ ПО РЕЗУЛЬТАТАМ АНАЛИЗА КОСМИЧЕСКИХ СНИМКОВ SENTINEL-2* \\ Табунщик В.А. ${ }^{1}$, Горбунов P.B. ${ }^{2}$, Даниленко А.А. ${ }^{3}$ \\ ${ }^{1}$ ФГБУН ФИЦ «Институт биологии южных морей имени А.О. Ковалевского РАН», 2. Севастополь, Российская Федерачия, e-mail: tabunshchyk@ya.ru \\ ${ }^{2}$ ФГБУН ФИЦ «Институт биологии южных морей имени А.О. Ковалевского РАН», 2. Севастополь, Российская Федерация, e-mail: karadag_station@mail.ru \\ ${ }^{3}$ Московское представительство ФГБУН ФИЦ «Институт биологии южных морей имени А.О. Ковалевского РАН», г. Москва, Российская Федерачия, e-mail: moscow@ibss-ras.ru
}

Цель исследования - изучить пространственное распределение значений вегетационного индекса Normalized Difference Vegetation Index (NDVI) и выявить слабоиспользуемые земли в сельском хозяйстве на территории города федерального значения Севастополь в 2017 году. Для расчетов вегетационного индекса Normalized Difference Vegetation Index (NDVI) были использованы космические снимки Sentinel-2 с минимальными показателями облачности за период с 16 февраля 2017 года по 29 октября 2017 года. Космические снимки были предварительно обработаны и прошли атмосферную коррекцию. Результаты исследования показывают, что на территории города федерального значения Севастополь в 2017 году средние значения вегетационного индекса Normalized Difference Vegetation Index (NDVI) колеблются достигают 0,61 . Выявлены семь участков сельскохозяйственных земель со средними значениями вегетационного индекса Normalized Difference Vegetation Index (NDVI) менеe 0,2, что свидетельствует о слабом развитии растительности и вовлечении в сельскохозяйственную деятельность.

Ключевые слова: Sentinel; NDVI; Крым; Крымский полуостров; Севастополь; вегетационный индекс.

\section{Введение}

В последние годы наблюдается интенсивный рост потребления сельскохозяйственных продуктов в связи с ростом численности населения на планете. В связи с этим необходимо постоянно улучшать эффективность выращивания сельскохозяйственных культур и повышать производительность сельского хозяйства. Для этого необходимо постоянно производить оперативный контроль (часто в режиме «он-лайн») над земельными ресурсами, в том числе сельскохозяйственными землями.

NDVI (Normalized Difference Vegetation Index, нормализованный разностный вегетационный индекс) - простой количественный показатель количества фотосинтетически активной биомассы. Один из самых распространенных и используемых индексов для решения задач, использующих количественные оценки растительного покрова. Для отображения NDVI используется стандартизированная дискретная (беспрерывная градиентная) шкала в диапазоне значений от +1 до -1 (Kriegler et al., 1969; Rouse et al., 1973). Для густой растительности значения NDVI

* Исследование выполнено в рамках темы НИР «Изучение пространственно-временной организации водных и сухопутных экосистем с иелью развития системы оперативного мониторинга на основе данных дистанционного зондирования и ГИС-технологий. Регистрационный номер: АААA-А19-119061190081-9». 
составляют $-0,7$; разреженной растительности $-0,5$; открытой почвы $-0,025$; воды $(-0,25)$; искусственных материалов - $(-0,5)$.

Вычисляется по следующей формуле:

$$
\mathrm{NDVI}=\frac{\mathrm{NIR}-\mathrm{RED}}{\mathrm{NIR}+\mathrm{RED}}
$$

где: NIR - отражение в ближней инфракрасной области спектра, RED - отражение в красной области спектра.

По формуле (1), значение каждого пикселя NDVI равно разнице интенсивностей отраженного света в красном и инфракрасном диапазоне, деленной на сумму их интенсивностей.

История использования NDVI берет свое начало с работ Kriegler F. J. с соавторами (Kriegler et al., 1969) и Rouse J. W. с соавторами (Rouse et al., 1973). Активное использование вегетационного индекса NDVI началось в конце 70-х-начале 80-х годов $\mathrm{XX}$ века. Существует большое количество работ, посвященных как теории расчета вегетационного индекса NDVI и его производных, так и конкретным практическим примерам его использования. Позднее стали разрабатываться различные модификации вегетационного индекса NDVI. Huete A. R. (Huete, 1988) предлагает использовать вегетационный индекс Soil-Adjusted Vegetation Index (SAVI) в котором вводится поправка на воздействие почвы и позволяет описывать динамические почвеннорастительные системы на основе данных дистанционного зондирования. Qi J. с соавторами (Qi et al., 1994) модернизировали Soil-Adjusted Vegetation Index (SAVI) и разработали вегетационные индексы Modified Soil Adjusted Vegetation Index (MSAVI) и Modified Soil Adjusted Vegetation Index 2 (MSAVI 2) позволяющие учитывать воздействия почвы путем включения поправочного коэффициента почвы $\mathrm{L}$ в знаменатель уравнения вегетационного индекса NDVI. Gao B. (Gao, 1996) предложил использовать Normalized Difference Water Index (NDWI), который чувствителен к изменениям содержания жидкой воды в растительных покровах. Однако NDWI менее чувствителен к атмосферным воздействиям, чем NDVI; NDWI менее эффективно справляется с нивилированием фоновых эффектов отражения почвы в отличие от NDVI. Gao B. (Gao, 1996) отмечает, что NDWI следует рассматривать как независимый вегетационный индекс, он дополняет, а не заменяет NDVI.

Aase J.K. и Siddoway F.H. (Aase, Siddoway, 1981) проводили спектральные измерения NDVI в вегетационный период и использовали вегетационный индекс NDVI для прогнозирования урожайности озимой пшеницы в конце вегетационного сезона в штате Монтана (США). Эта работа одной из первых определила высокий потенциал применения вегетационных индексов при изучении сельскохозяйственных культур. В большинстве работ подчеркивается, что использование космических снимков для расчета вегетационных индексов имеет огромные перспективы для мониторинга растительности (Tucker et al., 1983; Norwine, Greegor, 1983; Justice et al., 1986; Justice, Hiernaux, 1986; Hiernaux, Justice, 1986; Lloyd, 1990). Изначально исследование значений индекса NDVI производилось для больших площадных объектов (материков, стран), что в первую очередь было связано с использованием космических снимков низкого разрешения - Townshend J. R. G. и Justice C.O. (Townshend, Justice, 1986), Justice B.O. и Hiernaux P.H.Y. (Justice et al., 1986; Justice, Hiernaux, 1986; Hiernaux, Justice, 1986), Groten S.M. (Groten, 1993) изучали распределение значений NDVI на территории Африки и отдельных стан Африки; Ріао S. с соавторами (2003) изучали межгодовые вариации NDVI в Китае с 1982 по 1999 год; Valor E. и Caselles V. (Valor, Caselles, 1996) изучали значения NDVI для Европы, Африки и Южной Америки; Gong D.-Y. и Shi P.-J. (Gong, Shi, 1993) анализировали связь изменения значений NDVI и изменения климата в 
пределах Евразии и др. Следует отметить что на современном этапе эти исследования не прекратились - а расширились, за счет включения ранее не исследованных или слабо исследованных территорий (Slayback et al., 2003; Cohen, Shoshany, 2002; Douglas Ramsey et al., 1995; Escuin et al., 2008).

Однако в последние годы наблюдается тенденция применения в исследованиях космических снимков высокого разрешения - Loveland T. R. с соавторами (Loveland et al., 2000) производили разработку глобальной базы данных характеристик почвеннорастительного покрова с покрытием 1 км; Wilson E.H. и Sader S.A. (Wilson, Sader, 2002) применяли изучение NDVI для определения лесозаготовок и изменения лесной древесной растительности; Li Z. и Fox J.M. (Li, Fox, 2012) использовали NDVI для картирования роста каучуковых деревьев в материковой части Юго-Восточной Азии; Wang Q. с соавторами (Wang et al., 2004) изучения лесов в Финляндии и др. При этом растет число публикаций, в которых авторы используют для расчетов NDVI данные спутников Landsat и Sentinel (Piedelobo et al., 2019; Onojeghuo et al., 2017; Mallinis et al., 2017; Weber et al., 2018; Urban et al., 2018; Teltscher et al., 2018; Teodoro, Amaral, 2019; Abd-Alwahab, Ghazal, 2019; Bezerra et al., 2018). Стоит так же отметить, что по данным реферативной базы Scopus лидирующие позиции в области изучения вегетационного индекса NDVI уверенно занимают китайские и американские исследователи, т.к. с Китаем и США аффилировано более 3000 работ различных исследователей. Сейчас ведущими научными организациями в этой сфере выступают Chinese Academy of Sciences, Beijing Normal University, University of Chinese Academy of Sciences, Ministry of Education China, NASA Goddard Space Flight Center.

В России первые работы по применению вегетационного индекса NDVI, как следует из поиска по научной электронной библиотеки, стали появляться в 90-х годах XX века (Антоновский и др., 1992; Антоновский и др., 1993; Байкалова и др., 1998; Харин, Грингоф, 2002), однако пик их пришелся на начало XXI века (Гунин и др., 2004; Рулев и др., 2016; Черепанов и др., 2009; Черепанова, Девятков, 2008; Пахучий, Пахучая, 2014; Братков и др., 2016; Шевела, Погорелов и др., 2010; Савин и др., 2015; Терехин и др., 2015; Табунщик и др., 2018), что связано с массовым развитием сети Интернет, доступом к персональным компьютерам и активным внедрение дистанционных, геоинформационных и космических методов исследования территорий и акваторий.

Изучение литературных данных показывает, что на сегодняшний день Normalized Difference Vegetation Index (NDVI) является самым распространенным среди вегетационных индексов, которые используются для расчетов и анализа состояния растений и культур в сельском хозяйстве.

\section{Материалы и методы}

Для расчета NDVI на территории города федерального значения Севастополь были использованы космические снимки Sentinel-2 (Copernicus Open..., 2019).

Общая методика исследования состоит в выполнении следующего алгоритма:

1. На сайте программы «Коперник» («Copernicus») выбираются космические снимки, покрывающие территорию города федерального значения Севастополь за выбранный период. Производится автоматическая загрузка многоканальных космических снимков.

Как отмечается в (Copernicus Open..., 2019), «Коперник» («Copernicus») - это программа Европейского Союза по наблюдению Земли, направленная на изучение нашей планеты и ее окружающей среды в интересах всех граждан. Она предлагает информационные услуги, основанные на спутниковых наблюдениях Земли и некосмических данных in situ. Программа координируется и управляется Европейской 
комиссией. Она осуществляется в партнерстве с государствами-членами Европейского Союза, Европейским космическим агентством (ЕКА), Европейской организацией по эксплуатации метеорологических спутников (EUMETSAT), Европейским центром среднесрочных прогнозов погоды (ECMWF), агентствами ЕC и Mercator Océan. Предоставляемые данные и информационные услуги являются свободно и открыто доступными для их пользователей сети Интернет.

Территория города федерального значения Севастополь находится в пределах квадрата T36TWQ, на сайте центра открытых данных программы «Коперник» Copernicus Open Access Hub (Copernicus Open..., 2019). В пределах квадрата T36TWQ попадают как полные космические снимки, покрывающие всю территорию и акваторию квадрата, так и не полные, охватывающие значительную часть акватории Черного моря, и только малую часть территории Крымского полуострова. Так как для расчетов NDVI необходимо покрытие на всю территорию города федерального значения Севастополь были использованы только полные квадраты.

В виду того что космические снимки могут иметь перекрытие облаками на этом этапе производится отсеивание космических снимков с высокой долей данного показателя. Так в январе 2017 года не было космических снимков, позволяющих производить расчеты, в феврале были выбраны 2 космических снимка за 16 февраля (доля облачности 2\%) и 26 февраля (доля облачности 52\%), в марте был выбран один космический снимок за 28 марта (доля облачности 1\%), в апреле - один космический снимок за 27 апреля (доля облачности 2\%), в мае - один космический снимок за 17 мая (доля облачности 10\%), в июне - три космических снимка за 6 июня (доля облачности 8\%), 16 июня (доля облачности 20\%) и 26 июня (доля облачности 6\%), в июле - пять космических снимков за 01 июля (доля облачности 0\%), 06 июля (доля облачности 5\%), 16 июля (доля облачности 23\%), 26 июля (доля облачности 1\%) и 31 июля (доля облачности 0\%), в августе - три космических снимка за 05 августа (доля облачности 0\%), 20 августа (доля облачности 1\%) и 25 августа (доля облачности 3\%), в сентябре - четыре космических снимка за 9 сентября (доля облачности 0\%), 14 сентября (доля облачности 0\%), 19 сентября (доля облачности 3\%) и 24 сентября (доля облачности 2\%), в октябре - два космических снимка за 04 октября (доля облачности 4\%) и 29 октября (доля облачности 10\%). Космические снимки за ноябрь и декабрь не учитывалась в виду невозможности производить по ним расчёты. Увеличение числа снимков во второй половине 2017 года связано с вводом в эксплуатацию второго спутника Sentinel-2 - Sentinel -2B.

Использование и не использование космических снимков с примерно с одинаковой долей облачности может так же быть связано с географическим распределением поля облачности. Так на ряде снимков облачность может достигать примерно 50\%, но ее географическое распределение характеризуется акваторией Черного моря в пределах квадрата съемки, и такие космические снимки могут быть использованы в работе. Чего не скажешь про космические снимки с долей облачности около 50\% но локализованной над территорией Крымского полуострова в пределах квадрата съемки. Одновременно с этим следует сделать оговорку - часть космических снимков с высокой облачностью может быть полезна для исследования локальных участков на территории города федерального значения Севастополь. Снимки со значением доли облачности более $20 \%$ в большей степени использовались для локального анализа и расчетов.

2. Полученные архивы многоканальных космических снимков подгружаются в программный комплекс Quantum GIS. B программном комплексе Quantum GIS c использованием модуля «Semi-Automatic Classification Plugin for QGIS» производится атмосферная коррекция космических снимков уровня «MSIL1C» с использованием «Apply DOS1 atmospheric correction». 
3. В программном комплексе Quantum GIS производится расчет NDVI по формуле (1) в программном комплексе Quantum GIS c использованием модуля «Калькулятор растров».

4. В программном комплексе Quantum GIS производится обработка полученных значений NDVI и макетирование карт распределения NDVI за рассматриваемый период.

\section{Результаты и обсуждение}

В результате по формуле (1) были рассчитаны значения NDVI для территории города федерального значения Севастополь, представленные в таблице 1 на рисунках 1-4.

Таблица 1.

Значение вегетационного индекса NDVI на территории города федерального значения Севастополь

\begin{tabular}{|c|c|c|c|c|c|c|}
\hline \multirow{2}{*}{ Дата } & \multicolumn{7}{|c|}{ Значение NDVI } \\
\cline { 2 - 7 } & Среднее & Медиана & $\begin{array}{c}\text { Стандартое } \\
\text { отклонение }\end{array}$ & Минимум & Максимум & Амплитуда \\
\hline 2017.02 .16 & 0,27 & 0,27 & 0,13 & $-0,54$ & 0,88 & 1,42 \\
\hline 2017.02 .26 & 0,32 & 0,33 & 0,11 & $-0,62$ & 1,00 & 1,62 \\
\hline 2017.03 .28 & 0,35 & 0,37 & 0,13 & $-0,58$ & 1,00 & 1,58 \\
\hline 2017.04 .27 & 0,48 & 0,51 & 0,16 & $-0,56$ & 0,94 & 1,50 \\
\hline 2017.05 .17 & 0,39 & 0,40 & 0,16 & $-0,24$ & 0,77 & 1,01 \\
\hline 2017.06 .06 & 0,58 & 0,60 & 0,22 & $-0,62$ & 1,00 & 1,62 \\
\hline 2017.06 .16 & 0,57 & 0,59 & 0,23 & $-0,71$ & 1,00 & 1,71 \\
\hline 2017.06 .26 & 0,56 & 0,58 & 0,23 & $-0,59$ & 1,00 & 1,59 \\
\hline 2017.07 .01 & 0,61 & 0,61 & 0,22 & $-0,46$ & 0,94 & 1,40 \\
\hline 2017.07 .06$. & 0,51 & 0,50 & 0,23 & $-0,44$ & 0,91 & 1,35 \\
\hline 2017.07 .16 & 0,57 & 0,56 & 0,24 & $-0,49$ & 1,00 & 1,49 \\
\hline 2017.07 .26 & 0,56 & 0,55 & 0,23 & $-0,40$ & 0,93 & 1,33 \\
\hline 2017.07 .31 & 0,54 & 0,52 & 0,24 & $-0,41$ & 0,97 & 1,38 \\
\hline 2017.08 .05 & 0,55 & 0,53 & 0,24 & $-0,48$ & 1,00 & 1,48 \\
\hline 2017.08 .20 & 0,52 & 0,50 & 0,23 & $-0,41$ & 0,90 & 1,31 \\
\hline 2017.08 .25 & 0,50 & 0,48 & 0,23 & $-0,61$ & 0,98 & 1,59 \\
\hline 2017.09 .09$. & 0,53 & 0,52 & 0,23 & $-0,45$ & 0,92 & 1,36 \\
\hline 2017.09 .14 & 0,52 & 0,50 & 0,23 & $-0,47$ & 1,00 & 1,47 \\
\hline 2017.09 .19 & 0,48 & 0,46 & 0,23 & $-0,51$ & 0,89 & 1,41 \\
\hline 2017.09 .24 & 0,48 & 0,46 & 0,23 & $-0,58$ & 0,89 & 1,46 \\
\hline 2017.10 .04 & 0,49 & 0,47 & 0,22 & $-0,47$ & 1,00 & 1,47 \\
\hline 2017.10 .19 & 0,38 & 0,38 & 0,24 & $-0,49$ & 1,00 & 1,49 \\
\hline 2017.10 .29 & 0,38 & 0,39 & 0,16 & $-0,55$ & 1,00 & 1,55 \\
\hline
\end{tabular}

Наличие отрицательных значений NDVI во всех рассматриваемых датах объясняется тем, что на территории города федерального значения Севастополь расположено крупное Чернореченское водохранилище, а также возможно попадание пикселей с акватории Черного моря. В работах (Kriegler et al., 1969; Rouse et al., 1973) подчеркивается, что для водных поверхностей значения NDVI принимают отрицательные значения. Наличие максимальных значений равных единице или близких к единице объясняется наличием больших массивов лесной растительности на юговостоке, где и локализованы пиксели с этими значениями.

В целом для оценки удобнее использовать и анализировать средние показатели значений NDVI. Как показано в работе (Табунщик и др., 2018) средние значения NDVI по всей рассматриваемой территории равны или отличаются в пределах $1 \%$ от средних значений NDVI только положительной части диапазона значений NDVI. 


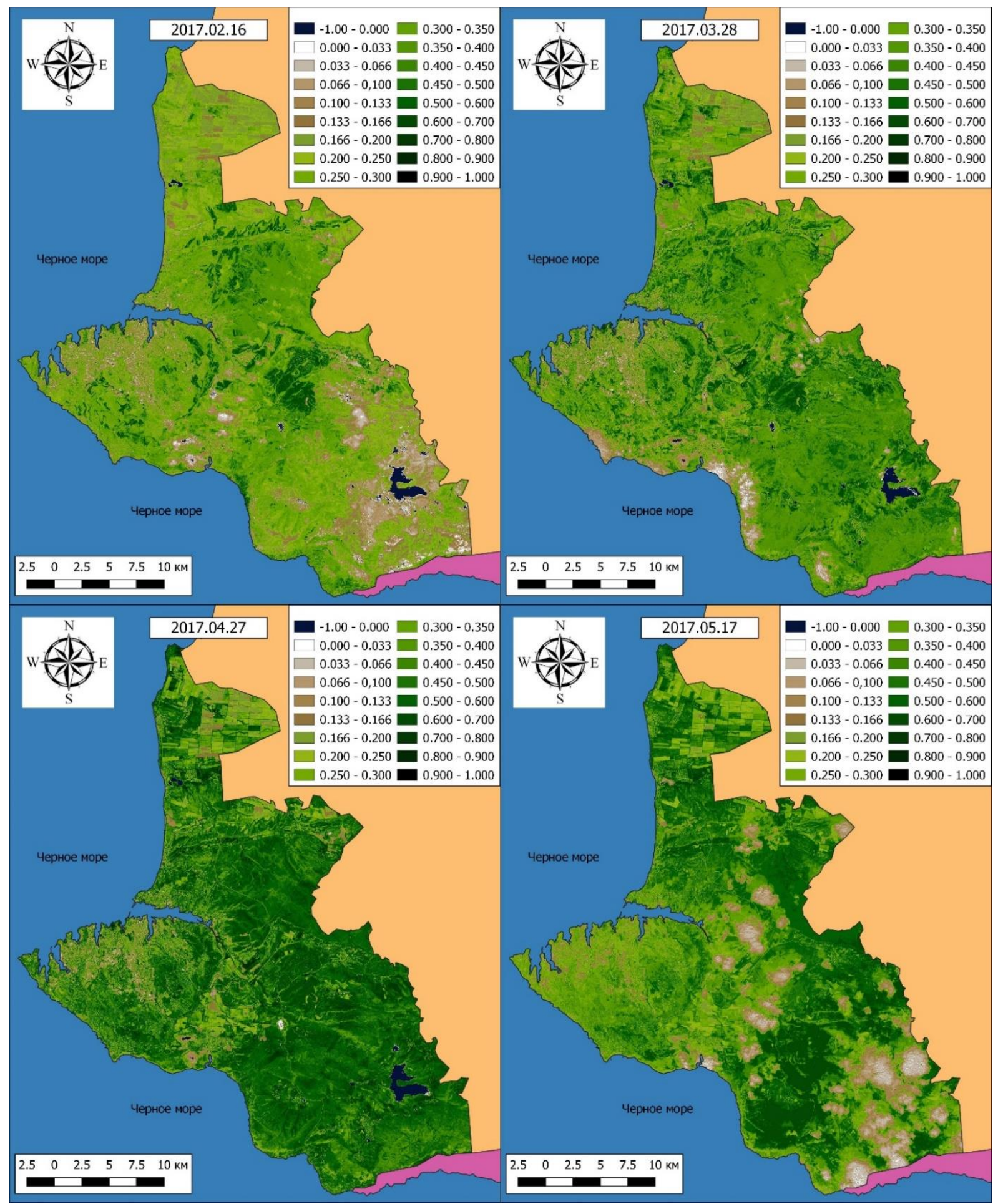

Рис. 1. Значения NDVI на территории город федерального значения Севастополь за 16 февраля 2017 года, 28 марта 2017 года, 27 апреля 2017 года и 17 мая 2017 года 


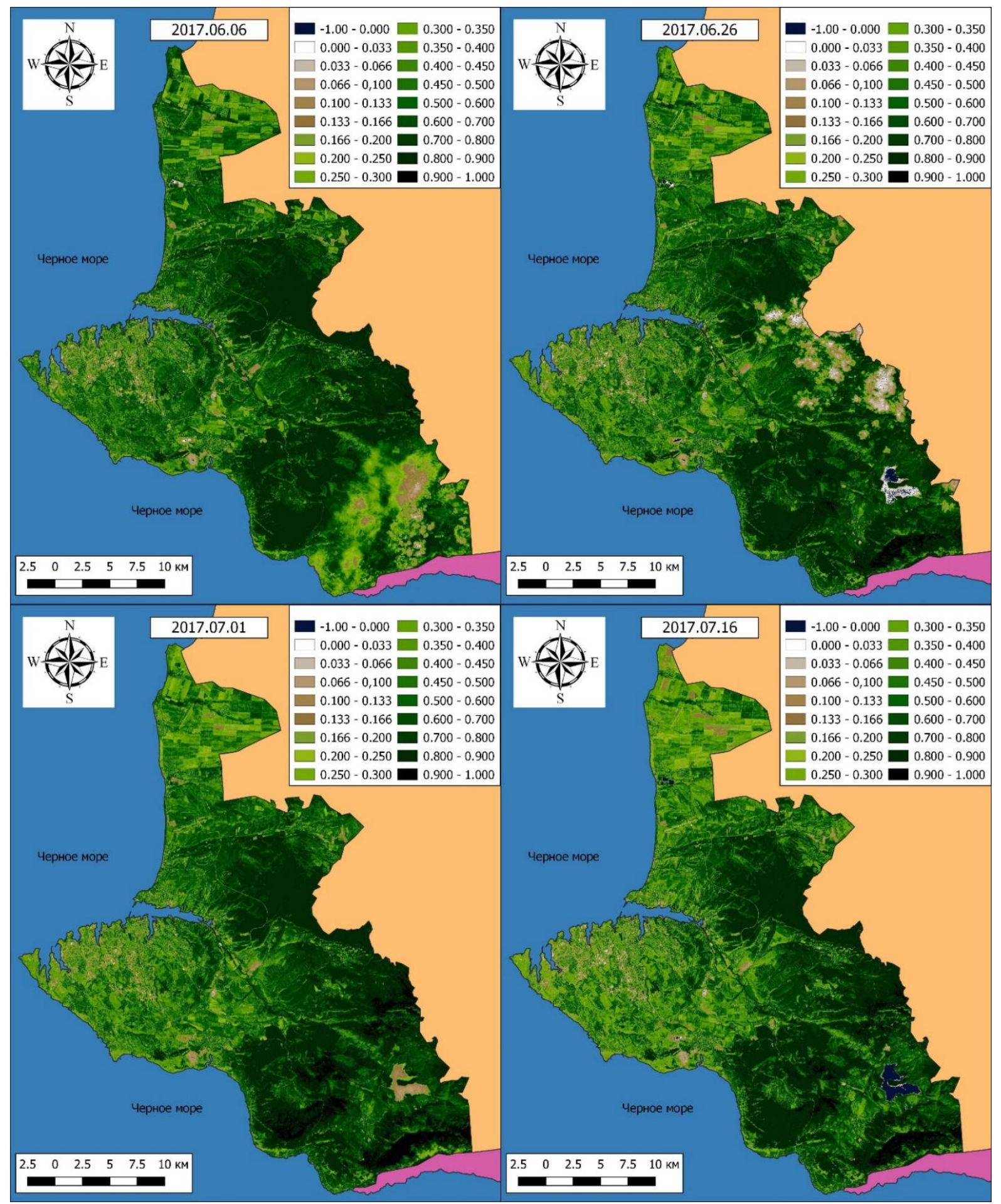

Рис. 2. Значения NDVI на территории город федерального значения Севастополь за 06 июня 2017 года, 26 июня 2017 года, 01 июля 2017 года и 16 июля 2017 года 


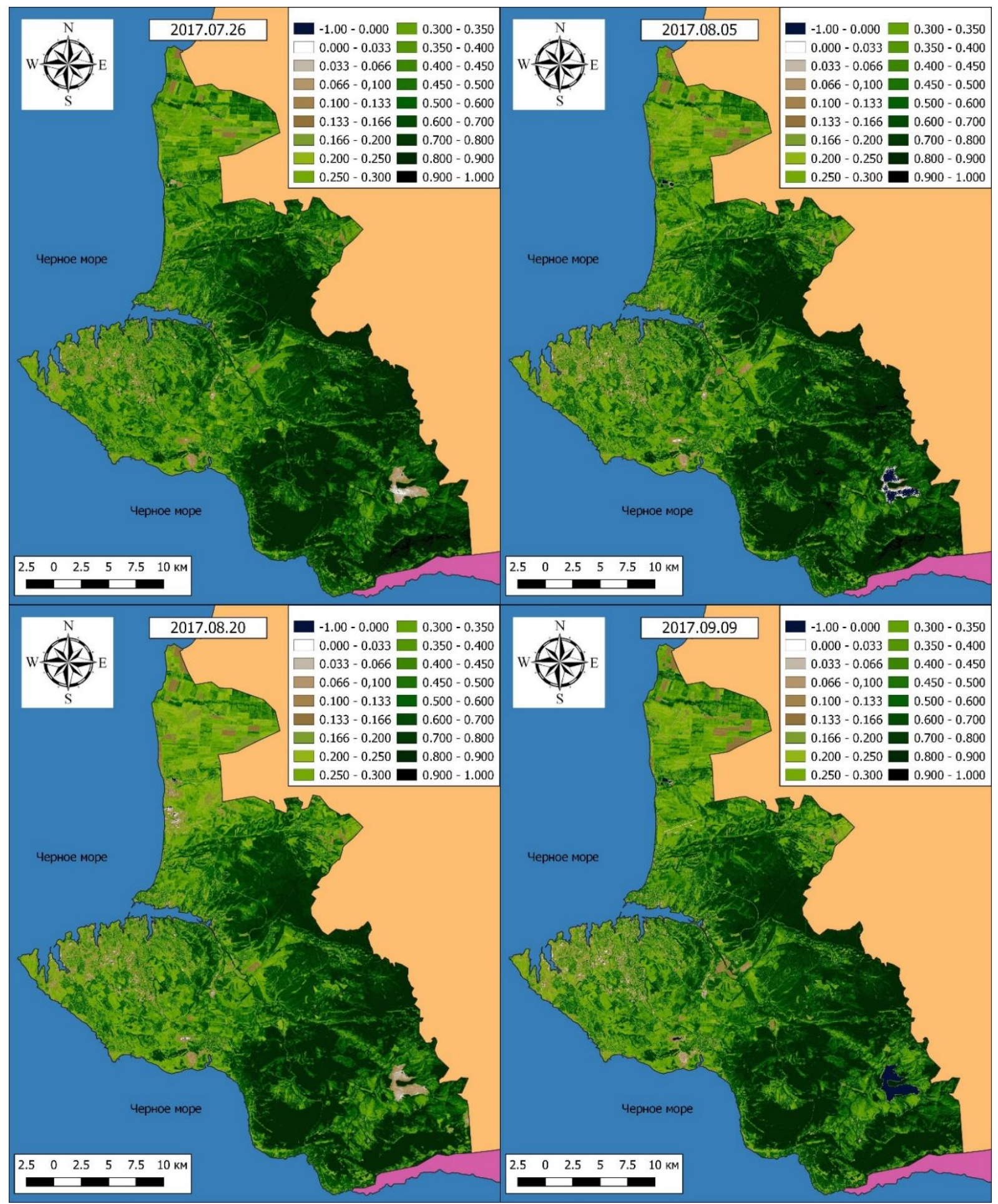

Рис. 3. Значения NDVI на территории город федерального значения Севастополь за 07 июля 2017 года, 05 августа 2017 года, 20 августа 2017 года и 09 сентября 2017 года 


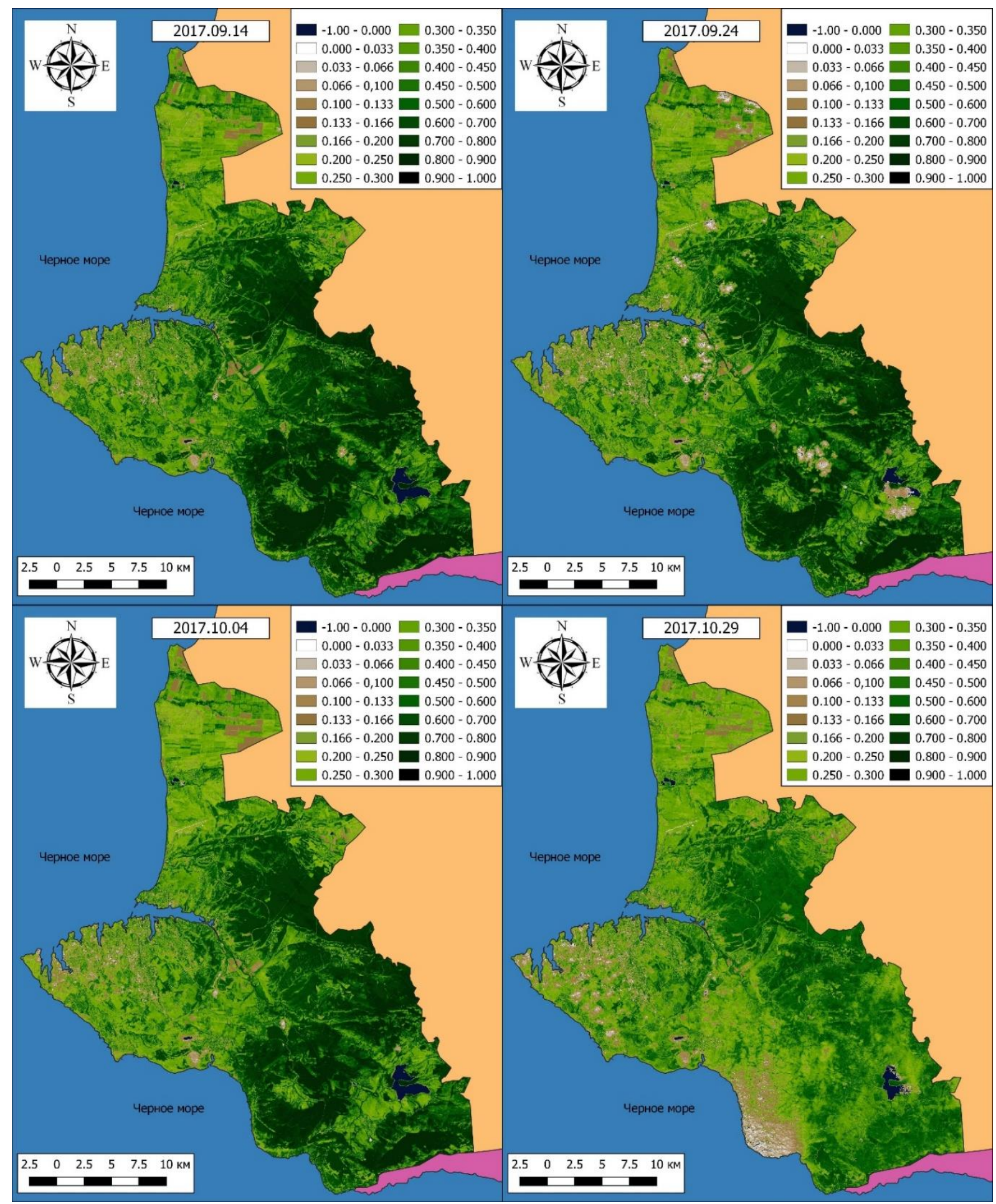

Рис. 4. Значения NDVI на территории город федерального значения Севастополь за 14 сентября 2017 года, 24 сентября 2017 года, 04 октября 2017 года и 29 октября 2017 года 
Для территории города федерального значения Севастополь установлено что минимальные средние значения NDVI в 2017 году приходятся на февраль и октябрь и составляют $0,3-0,4$.

Одновременно с этим нужно сказать, что небольшие значения, выделяющиеся из общего ряда, для мая и частично июня, июля и августа объясняется присутствием облачности на космических снимках. Если для июня, июля и августа 2017 года представляется возможным использовать соседние даты для построения целостной картины распределения значений NDVI, то для мая имеется единичный снимок, частично удовлетворяющий условиям исследования.

Однако для анализа неиспользуемых земель эти космические снимки представляют ценность. Максимальными средними значениями NDVI характеризуются летние месяцы 2017 года, особенно июль, где максимальный средний показатель значений NDVI достигает 0,61. Равенство средних значений и медианы выборки значений NDVI свидетельствует о нормальном распределении выборки. По сравнению с ранее проведенными исследованиями (Табунщик и др., 2018), территория города федерального значения Севастополь характеризуется довольно высокими минимальными и максимальными показателями значений NDVI, что связано в первую очередь с наличием территорий покрытых лесной растительностью.

Пространственное распределение значений NDVI на территории города федерального значения Севастополь неоднородно. Стабильно высокими значениями NDVI в течении всего рассматриваемого периода характеризуется юго-восточная часть, где произрастает большое количество древесной многолетней растительности.

Территория Гераклейского полуострова, занятая городской застройкой и другие населенные пункты, учитывая их внутреннюю планировочную организацию в целом обладают низкими значениями NDVI. На северо-западе, где сосредоточены основные сельскохозяйственные земли, наблюдается высокие показатели значений NDVI, однако они напрямую зависят от характера возделываемых сельскохозяйственных культур.

Для анализа неиспользуемых земель на территории города федерального значения Севастополь с помощью космических снимков и полевого картирования определены границы земельных участков, занимаемые различными сельскохозяйственными культурами. Выявление неиспользуемых земель строилось исходя из предположения что значения NDVI для таких участков должны быть менее 0,2, что свидетельствует об отсутствии растительности или ее крайне слабом, угнетенном развитии. Учитывая большой объем информации, полученный при расчетах значений NDVI, визуальный ручной анализ занимает большое количество времени и слабо подходит для этих целей. Решение этой задачи выполнялось с использованием запросов к базе данных. Для этого для каждого участка были получены средние значения NDVI для каждой из рассматриваемой дат. Путем задания запросов были выбраны участки где в течении рассматриваемого периода значения NDVI менее 0,2 . Всего было обнаружено семь таких участков (в районе населённых пунктов Солнечное и Пироговка). Колебания значений NDVI в пределах 0,1-0,2 в большей мере свидетельствуют о сильно угнетенном состоянии растительности, нежели о ее отсутствии.

Представляет собой интерес распределения значений NDVI по ландшафтным уровням на территории города федерального значения Севастополь. Рассмотрим распределение NDVI по ландшафтным уровням Крымского полуострова в трактовке Г.Е. Гришанкова, в пределах города федерального значения Севастополь (рис. 5).

Как видно из рисунка 5 наибольшими средними значениями обладает среднегорный ландшафтный уровень, а наименьшими - гидроморфный ландшафтный уровень. Как показано в работе А.С. Рулева с соавторами (Рулев и др., 2016), NDVI тесным образом связан с продуктивностью и эти два показателя имеют высокую корреляционную связь. 


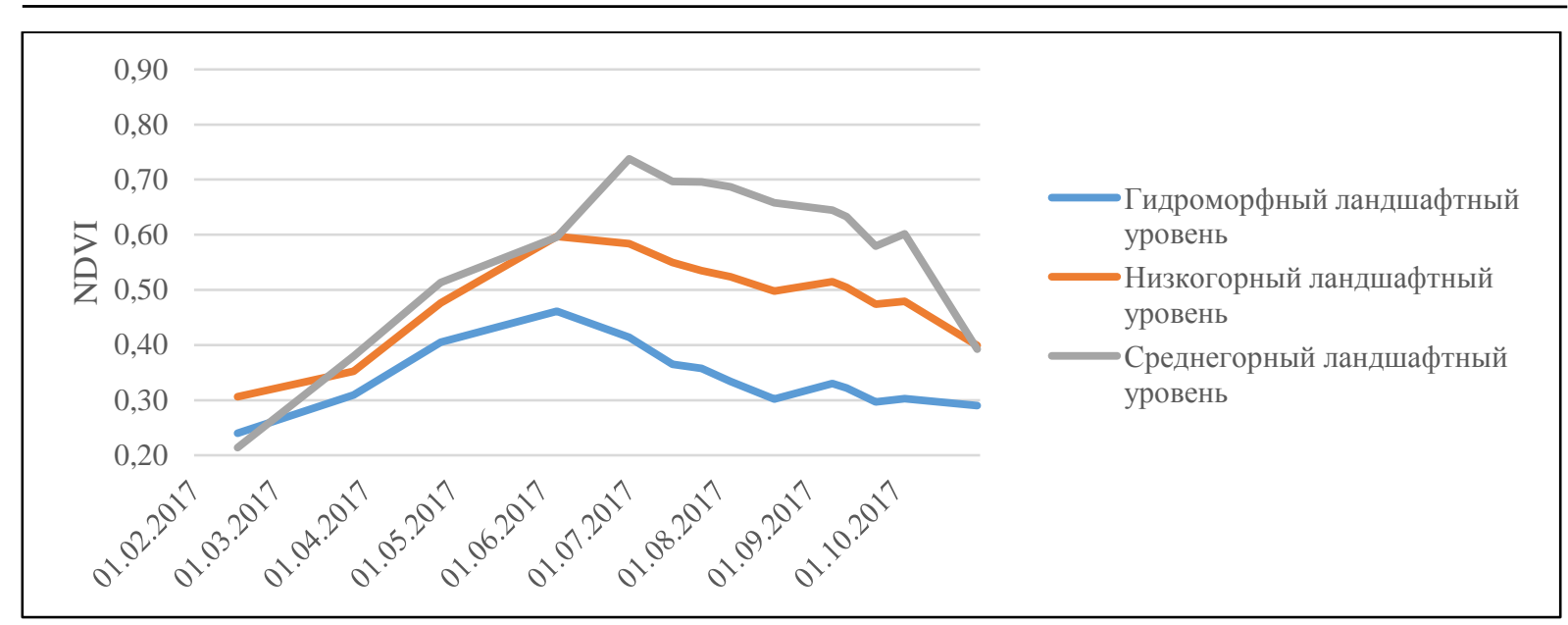

Рис. 5. Распределение значений NDVI в пределах ландшафтных уровней Крымского полуострова в пределах территории города федерального значения Севастополь

Поэтому можно утверждать, что в пределах территории города федерального значения Севастополь среднегорный ландшафтный уровень обладает большей продуктивностью, чем низкогорный и плакорный. Косвенно этому находится подтверждение в том, что гидроморфный ландшафтный уровень наиболее сильно преобразован хозяйственной деятельностью, а среднегорный ландшафтный уровень наименее. К тому же среднегорный ландшафтный уровень наиболее сильно облесен. Дополнительно, можно утверждать, что ландшафты гидроморфного ландшафтного уровня потеряли часть своей продуктивности из-за хозяйственного освоения.

\section{Выводы}

Территория города федерального значения Севастополь имеет довольно сложную структуру землепользования, в которой отсутствуют территории под зерновые культуры. Сельскохозяйственные земли в основном представлены в северо-западной части города федерального значения Севастополь и вдоль долин крупных рек. Исследование значений NDVI показало, что практически все сельскохозяйственные земли на территории города федерального значения Севастополь активно используются. Максимальные значения NDVI достигаются на юго-востоке города федерального значения Севастополь где произрастают леса, минимальные - в пределах населенных пунктов.

\section{Список литературы}

1. Антоновский М.Я., Бухштабер В.М., Векслер Л.С. Применение многомерного статистического анализа для обнаружения структурных изменении во временных рядах данных экологических наблюдении // Проблемы экологического мониторинга и моделирования экосистем. - 1993. - Т. 15. - С. 193-213.

2. Антоновский М.Я., Бухштабер В.М., Векслер Л.С., Малингро Ж.П. Статистический анализ данных по глобальному индексу вегетации // Проблемы экологического мониторинга и моделирования экосистем. - 1992. - Т. 14. - С. 153-172.

3. Байкалова Т.В., Евтюшкин А.В., Жилин С.И., Юшаков В.Н. Мониторинг состояния земных покровов Алтая по данным ИС3 "NOAA" // Известия Алтайского государственного университета. - 1998. - № 1 (5). - С. 49-52.

4. Братков В.В., Кравченко И.В., Туаев Г.А., Атаев З.В., Абдулжалимов А.А. Применение вегетационных индексов для картографирования ландшафтов Большого 
Кавказа / // Известия Дагестанского государственного педагогического университета. Естественные и точные науки. - 2016. - Т. 10. - № 4. - С. 97-111.

5. Гунин П.Д., Золотокрылин А.И., Виноградова В.В., Бажа С.Н. Динамика состояния растительного покрова южной Монголии по данным NDVI // Аридные экосистемы. - 2004. - T. 10. - № 24-25. - С. 29-35.

6. Пахучий В.В., Пахучая Л.М. Опыт использования вегетационных индексов при комплексных исследованиях на объектах гидролесомелиорации // Вестник Поволжского государственного технологического университета. Сер.: Лес. Экология. Природопользование. - 2014. - № 1 (21). - С. 33-41.

7. Рулев А.С., Канищев С.Н., Шинкаренко С.С. Анализ сезонной динамики NDVI естественной растительности Заволжья Волгоградской области // Современные проблемы дистанционного зондирования Земли из космоса. - 2016. - Т. 13. - № 4. C. $113-123$.

8. Савин Ю.И., Танов Э.Р., Харзинов С. Использование вегетационного индекса NDVI для оценки качества почв пашни (на примере Баксанского района КабардиноБалкарии) // Бюллетень Почвенного института им. В.В. Докучаева. - 2015. - Вып. 77. - C. 51-65.

9. Табунщик В.А., Петлюкова Е.А., Хитрин М.О. Применение спутниковых снимков Sentinel-2 для анализа земель используемых в сельском хозяйстве (на примере Раздольненского района Республики Крым) // Труды Карадагской научной станции им. Т.И. Вяземского - природного заповедника РАН. - 2018. - № 1 (5). - С. 43-57.

10. Терехин Э.A. Оценка сезонных значений вегетационного индекса (NDVI) для детектирования и анализа состояния посевов сельскохозяйственных культур // Исследование Земли из космоса. - 2015. - № 1. - С. 23-31.

11. Харин Н.Г., Грингоф И.Г. Концептуальный подход к использованию вегетационного индекса для оценки деградации засушливых земель // Метеорология и гидрология. 2002. - № 7. - С. 83-93.

12. Черепанов А.С., Дружинина Е.Г. Спектральные свойства растительности и вегетационные индексы // Геоматика. - 2009. - № 3. - С. 28-32.

13. Черепанова Е.С., Девятков С.Ю. Использование индекса растительности (NDVI) как метода контроля за состоянием лесных ресурсов Пермского края // Геоинформационное обеспечение пространственного развития Пермского края. Пермь: Пермский государственный университет, 2008. - С. 155-166.

14. Шевела С.Ю., Погорелов А.В. Вегетационный индекс NDVI как индикатор ландшафтов Краснодарского края // Географические исследования Краснодарского края. - 2010. - Выпуск 5. - С. 262-268.

15. Aase J.K., Siddoway F.H. Assessing winter wheat dry matter production via spectral reflectance measurements // Remote Sensing of Environment. - 1981. - V. 11. - № C. pp. 267-277.

16. Abd-Alwahab N.S., Ghazal N.K. Change Detection between Landsat 8 images and Sentinel2 images // Iraqi Journal of Science. - 2019. - V. 60. - № 8. - pp. 1868-1876.

17. Bezerra U.A., Oliveira L.M.M., Candeias A.L.B., Silva B.B., Leite A.C.L.S., Silva L.T.M.S. Comparison of the normalized difference vegetation index (NDVI) between the sensors olilandsat satellite-8 and msi-sentinel-2 satellite in semi-arid region // Anuario do Instituto de Geociencias. - 2018. - V. 41. - № 3. - pp. 167-177.

18. Cohen Y., Shoshany M. A national knowledge-based crop recognition in Mediterranean environment // ITC Journal. - 2002. - V. 2002. - № 4. - pp. 75-87.

19. Copernicus Open Access Hub [Электронный pecypc]. Режим доступа: https://scihub.copernicus.eu/dhus/\#/home (дата обращения 02.09.2019). 
20. Douglas Ramsey R., Falconer A., Jensen J.R. The relationship between NOAA-AVHRR NDVI and ecoregions in Utah // Remote Sensing of Environment. - 1995. - V. 53. - № 3. - pp. 188-198.

21. Escuin S., Navarro R., Fernández P. Fire severity assessment by using NBR (Normalized Burn Ratio) and NDVI (Normalized Difference Vegetation Index) derived from LANDSAT TM/ETM images // International Journal of Remote Sensing. - 2008. - V. 29. -№ 4. - pp. 1053-1073.

22. Gao B. NDWI - A normalized difference water index for remote sensing of vegetation liquid water from space // Remote Sensing of Environment. - 1996. - V. 58. - № 3. - pp. 257266.

23. Gong $D$., Shi $P$. Northern hemispheric NDVI variations associated with large-scale climate indices in spring // International Journal of Remote Sensing. - 1993. - V. 24. - № 12. - pp. 2559-2566.

24. Groten S.M. NDVI-crop monitoring and early yield assessment of Burkina Faso // International Journal of Remote Sensing. - 1993. - vol. 14. - № 8. - pp. 1495-1515.

25. Hiernaux P.H.Y., Justice C.O. Suivi du développement végétal au cours de l'été 1984 dans le Sahel Malien // International Journal of Remote Sensing. - 1986. - V. 7. - № 11. - pp. 1515-1531.

26. Huete A. R. A Soil-Adjusted Vegetation Index (SAVI) // Remote Sensing of Environment. - 1988. - vol. 25. - pp. 295-309.

27. Justice B.O., Hiernaux P.H.Y. Monitoring the grasslands of the sahel using NOAA AVHRR data: Niger 1983 // International Journal of Remote Sensing. - 1986. - V. 7. - № 11. - pp. 1475-1497.

28. Justice B.O., Holben B.N. Gwynne M.D. Monitoring east african vegetation using AVHRR data // International Journal of Remote Sensing. - 1986. - V. 7. - № 11. - pp. 1453-1474.

29. Kriegler F. J., Malila W. A., Nalepka R. F., Richardson W. Preprocessing transformations and their effects on multispectral recognition // Proceedings of the Sixth International Symposium on Remote Sensing of Environment. - Ann Arbor: University of Michigan, 1969. - pp. 97-131.

30. Li Z., Fox J.M. Mapping rubber tree growth in mainland Southeast Asia using time-series MODIS $250 \mathrm{~m}$ NDVI and statistical data // Applied Geography. - 2012. - V. 32. - № 2. pp. 420-432.

31. Lloyd D. A phenological classification of terrestrial vegetation cover using shortwave vegetation index imagery // International Journal of Remote Sensing. - 1990. - V. 11 (12). pp. 2269-2279. - doi:10.1080/01431169008955174

32. Loveland T. R., Reed B. C., Brown J. F., Ohlen D. O., Zhu Z., Yang L., Merchant J. W. Development of a global land cover characteristics database and IGBP DISCover from 1 km AVHRR data // International Journal of Remote Sensing. - 2000. - V. 21 (6-7). pp. 1303-1330. - doi:10.1080/014311600210191

33. Mallinis G., Mitsopoulos I., Chrysafi I. Evaluating and comparing Sentinel 2A and Landsat8 Operational Land Imager (OLI) spectral indices for estimating fire severity in a Mediterranean pine ecosystem of Greece // GIScience \& Remote Sensing. - 2017. V. 55(1). - pp. 1-18. - doi:10.1080/15481603.2017.1354803

34. Norwine J., Greegor D. H. Vegetation classification based on advanced very high resolution radiometer (AVHRR) satellite imagery // Remote Sensing of Environment. - 1983. V. 13(1). - pp. 69-87. - doi:10.1016/0034-4257(83)90028-7

35. Onojeghuo A.O., Blackburn G.A., Wang Q., Atkinson P.M., Kindred D., Miao Y. Mapping paddy rice fields by applying machine learning algorithms to multi-temporal Sentinel-1A and Landsat data // International Journal of Remote Sensing. - 2017. - V. 39 (4). pp. 1042-1067. - doi:10.1080/01431161.2017.1395969 
36. Piao S., Fang J., Zhou L., Guo Q., Henderson M., Ji W., Li Y., Tao S. Interannual variations of monthly and seasonal normalized difference vegetation index (NDVI) in China from 1982 to 1999 // Journal of Geophysical Research D: Atmospheres. - 2003. - V. 108. - № 14. - pp. ACL 1-1 - ACL 1-13.

37. Piedelobo L., Hernández-López D., Ballesteros R., Chakhar A., Del Pozo S., GonzálezAguilera D., Moreno M. A. Scalable pixel-based crop classification combining Sentinel-2 and Landsat-8 data time series: Case study of the Duero river basin // Agricultural Systems. - 2019. - V. 171. - pp. 36-50. - doi:10.1016/j.agsy.2019.01.005

38. Qi J., Chehbouni A., Huete A.R., Kerr Y.H., Sorooshian S.A Modified Soil Adjusted Vegetation Index // Remote Sensing Of Environment. 1994. - V. 48 (2). - pp. 119-126. doi:10.1016/0034-4257(94)90134-1

39. Rouse J.W., Haas R.H., Schell J.A., Deering D.W. Monitoring vegetation systems in the great plains with ERTS // Third ERTS Symposium, NASA SP-351. - 1973. - V. 1. pp. 309-317.

40. Slayback D.A., Pinzon J.E., Los S.O., Tucker C.J. Northern hemisphere photosynthetic trends 1982-99 // Global Change Biology. - 2003. - V. 9. - № 1. - pp. 1-15.

41. Teltscher K., Fassnacht F.E. Using multispectral Landsat and Sentinel-2 satellite data to investigate vegetation change at Mount St. Helens since the great volcanic eruption in 1980 // Journal of Mountain Science. - 2018. - V. 15 (9). - pp. 1851-1867. doi:10.1007/s11629-018-4869-6

42. Teodoro A., Amaral A. A statistical and spatial analysis of portuguese forest fires in summer 2016 considering landsat 8 and sentinel 2A data // Environments - MDPI. - 2019. - V. 6. - № 3. - P. 36.

43. Townshend J.R.G., Justice C.O. Analysis of the dynamics of african vegetation using the normalized difference vegetation index // International Journal of Remote Sensing. - 1986. - V. 7. - № 11. - pp. 1435-1445.

44. Tucker C., Vanpraet C., Boerwinkel E., Gaston A. Satellite remote sensing of total dry matter production in the Senegalese Sahel // Remote Sensing of Environment. - 1983. V.13(6). - pp. 461-474. - doi:10.1016/0034-4257(83)90053-6.

45. Urban M., Berger C., Mudau T., Heckel K., Truckenbrodt J., Onyango Odipo V., Schmullius $C$. Surface Moisture and Vegetation Cover Analysis for Drought Monitoring in the Southern Kruger National Park Using Sentinel-1, Sentinel-2, and Landsat-8 // Remote Sensing. 2018. - V. 10 (9). - pp. 1482. - doi:10.3390/rs10091482

46. Valor E., Caselles V. Mapping land surface emissivity from NDVI: Application to European, African, and South American areas // Remote Sensing of Environment. - 1996. - V. 57. - № 3. - pp. 167-184.

47. Wang Q., Tenhunen J., Dinh N.Q., Reichstein M., Vesala T., Keronen P. Similarities in ground- and satellite-based NDVI time series and their relationship to physiological activity of a Scots pine forest in Finland // Remote Sensing of Environment. - 2004. - V. 93. - № 12. - pp. 225-237.

48. Weber D., Schaepman-Strub G., Ecker, K. Predicting habitat quality of protected dry grasslands using Landsat NDVI phenology // Ecological Indicators. - 2018. - V. 91. pp. 447-460. - doi:10.1016/j.ecolind.2018.03.081

49. Wilson E.H., Sader S.A. Detection of forest harvest type using multiple dates of Landsat TM imagery // Remote Sensing of Environment. - 2002. - V. 80(3). - pp. 385-396. doi:10.1016/s0034-4257(01)00318-2 
EVALUATION OF NORMALIZED DIFFERENCE VEGETATION INDEX (NDVI) IN 2017 ACCORDING TO THE ANALYSIS OF SPACE IMAGERY SENTINEL-2 IN SEVASTOPOL

Tabunshchik V.A. ${ }^{1}$, Gorbunov R.V. ${ }^{2}$, Danilenko A.A. ${ }^{3}$

${ }^{I}$ A.O. Kovalevsky Institute of Biology of the Southern Seas of RAS, Sevastopol, Russian Federation, e-mail: tabunshchyk@ya.ru

${ }^{2}$ A.O. Kovalevsky Institute of Biology of the Southern Seas of RAS, Sevastopol, Russian Federation, e-mail: karadag_station@mail.ru

${ }^{3}$ Moscow representative office A.O. Kovalevsky Institute of Biology of the Southern Seas of RAS, Moscow, Russian Federation, e-mail:moscow@ibss-ras.ru

In this article the spatial distribution of the values of Normalized Difference Vegetation Index (NDVI) on the territory of Sevastopol in 2017 was determined and underutilized lands in agriculture on the territory of Sevastopol in 2017 was identified. Sentinel-2 satellite images with minimal cloud cover for the period from February 16, 2017 to October 29, 2017 were used to calculate Normalized Difference Vegetation Index (NDVI). The satellite images were pre-processed and underwent atmospheric correction. The results of the study show that in the territory of the Federal city of Sevastopol in 2017, the average values Normalized Difference Vegetation Index (NDVI) fluctuate reach 0.61. Seven plots of agricultural land were identified with average values of Normalized Difference Vegetation Index (NDVI) less than 0.2, which indicates a weak vegetation development and involvement in agricultural activities.

Keywords: Sentinel; NDVI; Crimea; Crimean Peninsula; Sevastopol; vegetation index.

Поступила в редакциию 9.11.2019 г. 